\title{
Teaching Semantic Prosody of English Verbs through the DDL Approach and its Effect on Learners' Vocabulary Choice Appropriateness in a Persian EFL Context
}

\author{
Niloofar Mansoory \\ English Department of Payame-Noor University of Rasht, Guilan, Iran \\ E-mail: nmansoory@gmail.com \\ Mohsen Jafarpour (corresponding author) \\ Payame-Noor University of Rasht, Guilan, Iran \\ E-mail: mohsenjafarpour_64@yahoo.com
}

Doi:10.7575/aiac.alls.v.5n.2p.149

Received: 05/03/2014

URL: http://dx.doi.org/10.7575/aiac.alls.v.5n.2p.149

Accepted: 11/04/2014

\begin{abstract}
This study examined teaching SP of English verbs through the data-driven learning (DDL) approach and its effect on learners' vocabulary choice appropriateness in the Persian English foreign language (EFL) context. In the present study, two male intact classes were selected. One of these two classes was randomly selected as a treatment group and another one as a control group. The treatment group was provided with SP instruction through the DDL approach. The control group was exposed to SP as well, but traditionally and not through a DDL approach. The corpora used in the DDL approach were the Brown corpus and British National Corpus (BNC). Pretests and posttests of vocabulary choice appropriateness were administered and a repeated-measures ANOVA was used to compare means of test scores within and between subjects. The results indicated that SP instruction through DDL was significantly an effective approach to improve EFL learners' vocabulary choice appropriateness.
\end{abstract}

Keywords: Semantic prosody, Data-driven learning, Vocabulary instruction, Vocabulary choice appropriateness

\section{Introduction}

Nowadays, it is observed that vocabulary teaching and learning has significant effect on communication and acquisition (Richards \& Renandya, 2002). On the other hand, L2 learners relying on just dictionaries and thesauri make a number of semantic errors as they provide denotational meaning of a lexical item and do not present the subtle implications embedded in contexts (Lee \& Liu, 2009).

In vocabulary instruction, in many cases, traditional teaching methods do not bring about native-like competence of English vocabulary so complements are necessary. Among these complements is teaching SP of vocabulary particularly of near synonyms through the DDL approach.

The term SP has been studied for at least two decades and a part of corpus-based research has centered on it. Partington (2004) argues that there are two forms of evaluative meaning: One form of evaluative meaning is connotative meaning which is obvious and in-build, for example items such as excessive and flabby have negative connotative meaning which are clear to language users. Another form of evaluative meaning is SP which is spread over a unit of language and goes well beyond the single word and is much less evident to language users.

According to Bednarek (2008), SP "refers to POS/NEG [positive/negative] connotation as well as more complex attitudinal connotations, affecting both single words and larger units of meaning such as phrases" (p.132). It is also defined as "word forms which have a tendency to be (or in some cases which are always) followed by words with certain connotations, basically positive or negative" (Zethsen, 2006, p.279). In short, it is a kind of (positive, negative, or neutral) connotative meaning which a word takes due to its consistent collocations.

As a case in point, the verb CAUSE is almost always associated with words such as difficulty, trouble, problem, and damage which are unpleasant and negative (Stubbs, 1995; cited in Xiao \& McEnery, 2006). A random selection of instances of the verb CAUSE in the BNC are the following:

1. terial and methods of warfare of a nature to CAUSE superfluous injury or unnecessary su

2. which are intended, or may be expected, to CAUSE widespread, ... severe damage to th

3. tment of neutral shipping, or prisoners, can CAUSE serious problems. The laws of war $\mathrm{m}$

4. ble and bruising or damaging the plant may $\underline{\mathrm{CAUSE}}$ an eruption of all green foliage. Divi

5. re unsatisfactory on a blind as they too will $\underline{\text { CAUSE }}$ an unattractive bulge on the roller. $\mathrm{w}$ 


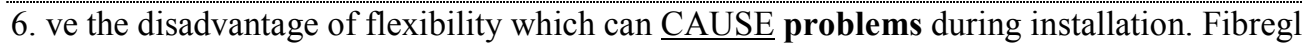

7. 1ters. Caddis flies The larvae of caddis flies CAUSE extensive damage to the flowers, leav

8. live and whether your exhibition is likely to CAUSE traffic congestion and aggravation to

9. $t$ perpetuate myths, reinforce stereotypes or CAUSE offence to particular groups or minorit

10. ger on the scene can create confusion and CAUSE distress. Changes of staff during the sl

The words indicating what entity is 'caused' in each line are highlighted in bold. In most cases this entity is one which would normally be considered to be undesirable.

On the other hand, the verb BRING ABOUT, which is in the same synonym-set with the verb CAUSE and therefore has the same denotational meaning as it, is usually followed by positive entities such as improvement and significant which are desirable (Xiao \& McEnery, 2006). Here is a random selection of instances of the verb BRING ABOUT in the same corpus:

1. $\mathrm{n}$, not only did the incoming millions BRING ABOUT innovations in agricultural method

2. equest the Sri Lankan government to BRING ABOUT an annulment of the amendment.

3. ct industry and commerce, and hence BRING ABOUT the creation of jobs. However, in o

4. dging that it is not law alone that can BRING ABOUT the changes we desire, but it is that

5. mpact: properly implemented it could BRING ABOUT improvements in the criminal justi

6. practise them repeatedly to be able to BRING ABOUT fairly rapid relaxation when tense

7. cts will be drawn together in order to BRING ABOUT better understanding of this care.

8. law, the Task Force has stepped in to BRING ABOUT correction. What of the future and

9. nises that a major effort is required to BRING ABOUT a fundamental change of attitude

10. s doing it.) 5. How do we attempt to BRING ABOUT a generic capacity for change am

C. Zhang (2010) states that "in a semantic prosody, there is nothing explicitly positive or negative for the node word. It is its characteristic collocates that have a similar particular semantic association" (p.192). Therefore, SP is not visible from the individual word itself, but it must be observed by the word's set of participants (Philip, 2010).

As choosing inappropriate words as a result of lack of knowledge of SP is very common among EFL learners of English (Xiao \& McEnery 2006; W. Zhang, 2009 among others), researchers have admitted the importance of SP for English second language (ESL)/EFL vocabulary instruction (W. Zhang, 2009). Furthermore, intuition is not effective enough to make learners aware of SP of lexical items (Louw, 2000; Stewart, 2010; Louw \& Chateau, 2010; C. Zhang, 2010). Although SP "does not belong to speakers' conscious knowledge of a language" (W. Zhang, 2009, p.3), native speakers are still able to understand the effects of it, of course, without ability to explain these effects (Louw \& Chateau, 2010). Broadly speaking, "native speaker intuition certainly can detect the usage of a word at odds with its semantic prosody" (Xiao \& McEnery, 2006, p.126) and SPs "are part of all [native] readers' prior knowledge" (Louw, 2000, p.3). In fact, concerning SP, the problem is with EFL learners who represent inappropriate vocabulary choice. "Learners' L2 intuition ... is inevitably less reliable than their L1 intuition" (Xiao and McEnery, 2006, p.126). Ahmadian, Yazdani, and Darabi (2011) showed that the knowledge of SP is insufficient in most Persian EFL learners in both receptive and productive mode and this lack of knowledge is obvious in all proficiency groups.

In traditional instruction of vocabulary especially verbs, teachers usually teach vocabulary by giving synonyms of them, among other things, without identifying their differences; and as Watter (1992) states in doing so, "important information about words is often missed, and it is easy to see how learners can be led to use words inappropriately" (p.129). Therefore, knowledge about the differences among near-synonyms is necessary to convey slight differences of meaning and to avoid undesirable implications (Inkpen \& Hirst, 2002). Among these distinguishing features is SP, that is, "near synonyms usually differ in their collocational behavior and semantic prosodies" (Xiao and McEnery, 2006, p.126). Poor synonym-choosing conveys undesired connotations, implications, and attitudes (Inkpen \& Hirst, 2006; Inkpen, 2007).

Nevertheless, this important information is not included in both monolingual and bilingual dictionaries, and it is "largely uncaptured by dictionary definitions" (Guo et al., 2011, p.417). Similarly, Ahmadian et al. (2011) argue that one of the possible reasons for students' poor performance in SP test is that most of monolingual dictionaries used by learners "have no or poor information" on SP (p.294). Positive SPs may be presented in bilingual dictionaries through translation equivalent, but this is not the case about negative semantic prosodies (Wang, 2004; cited in W. Zhang, 2009).

What does matter here is how to present SP in an effective way. Most writers recognized that SP can be recovered only by corpus analysis (Louw, 2000; Lee \& Liu 2009; Louw \& Chateau, 2010; C. Zhang, 2010). Corpus analysis can give EFL learners the opportunity to even surpass the native speakers' intuition in judgment on SP (Louw and Chateau, 2010). As non-native speakers, "only through interpreting large numbers of instances of a word or phrase can we observe semantic prosody" (W. Zhang, 2009, p.3). In other words, SP "can only be reliably observed in a large number of keyword-in-centre (KWIC) concordances" (Xiao \& McEnery, 2006, p.126). 
Additionally, working out words from the context to observe the collocations which accompany a specific word appears to be a revolutionary way to learn semantic behavior particularly SP of vocabulary, and many research problems including semantic issues can be settled by language data access possibility and statistical summarization functions of concordancing tools (Lee and Liu, 2009). It is, in fact, "in DDL [that] sorted concordances of words and phrases are presented to students, who [can] induce meanings and identify form-function relationships and patterns of semantic prosody" (Reinhardt, 2010, p.244). It "rests on a methodology which can uncover facts about language hitherto unexplored" (Flowerdew, 2009, p.395). Surprisingly, a little research has been done about SP; and there are not any reports of teaching prosodic behavior of lexical items particularly verbs and their near-synonyms through the DDL approach, and its effectiveness on young students' vocabulary choice appropriateness in an EFL context. "Practical and empirical research, therefore, will be needed with respect to how semantic prosody may be effectively integrated into ESL/EFL vocabulary teaching and learning" (W. Zhang, 2009, p.10). Therefore, the DDL approach for learning or teaching of lexis in context should be proposed to present SP features of vocabulary (C. Zhang, 2010). Consequently, the present study seeks to fill the gap and supplement the existing studies of SP literature by reporting on the following research hypothesis:

1- Teaching SP of English verbs through the DDL approach has a significant effect on learners' vocabulary choice appropriateness in an EFL context.

\subsection{Semantic Prosody}

Semantic prosody, also called semantic harmony (Lewandowska-Tomaszczyk, 1996), is a relatively new concept in linguistic field. The concept first emerged in the writing of Sinclair (1991) who claimed that "many uses of words and phrases show a tendency to occur in a certain semantic environment" (p.112). However, the term SP was first discussed in details by Louw (1993) (Ahmadian et al., 2011).

Semantic prosody "describes the consistent aura of meaning that is created through the general tendencies of the set of collocates associated with the central node word" (Louw \& Chateau, 2010, p.755). Also worth mentioning is that the main function of SP is to express speakers' or writers' attitude or evaluation.

When SP condition is violated some effects for example irony, insincerity, or humor can be resulted in the hearer (Louw, 2000). However, as Bednarek (2008) claims that is the case "only if lexical items exhibit a very strong preference" (p.127).

A phrase or a clause may also have a SP; for instance the phrase PAR FOR THE COURSE (Channell, 2000; cited in W. Zhang, 2009) has a negative SP. SP can also be associated with grammatical principle, for example as Louw (1993) observed BUILD UP has a positive SP when it is used transitively and it has a negative SP when it is used intransitively (W. Zhang, 2009). Finally, it is worth noting that not all lexical items have a SP; "semantic prosodies seem to be inconstant friends" (Philip, 2010, p.1).

Table 1. Examples of SPs (Xiao \& McEnery, 2006)

\begin{tabular}{lll}
\hline Author & Negative prosody & Positive prosody \\
\hline Sinclair (1991) & BREAK out & \\
& HAPPEN & \\
& SET in & \\
& {$[$ be] bent on } & BUILD up a [transitive] \\
Louw (1993, 2000) & [be] build up of [intransitive] & \\
& END up verbing & PROVIDE \\
Stubbs (1995, 1996) & GET oneself verbed & \\
Partington (1998) & ACCOST & \\
& CAUSE & \\
Hunston (2002) & COMMIT & \\
Schmitt and Carter (2004) & PEDDLE & \\
\hline
\end{tabular}

Table 1- adapted from Xiao and McEnery (2006) - is given as a brief summary of verbs whose conditions (positive, negative and neutral) had already been determined by different researchers.

Semantic prosody instruction has considerable benefits for EFL learners. Some of them are mentioned here:

1- Awareness of semantic prosody is helpful in both interpreting a text producer's hidden attitudes and understanding how to use lexical items appropriately (W. Zhang, 2009).

2- By being aware of SP of lexical items, learners can use them to communicate effectively (Xiao \& McEnery, 2006).

3- "The knowledge of SP can also provide insight into the teaching of vocabulary, especially near synonyms" (C. Zhang, 2010, p. 193). 
4- From the traditional view, near synonyms can be differentiated through experience and intuition, but SP provides a new way to distinguish them (Fan, 2010).

5- Being unaware of knowledge of SP causes learners to make pragmatic errors (Siepmann, 2005; cited in W. Zhang, 2009).

Actually, the necessity of being aware of SP of lexical items is inevitable for EFL learners as a big number of inappropriate vocabulary choice by learners (and sometimes their teachers) may stem from ignorance of this knowledge. Lack of the knowledge of SP may also reveal non-native language competence. Therefore, this knowledge "should be transferred to second language learners" (C. Zhang, 2010, p.193) and to do this, SP "should be integrated into ESL/EFL vocabulary teaching to help develop language learners' communicative competence" (W. Zhang, 2009, p. 9).

\subsection{Data-Driven Learning}

Over the last decades corpora evidence has been used both in linguistic research and teaching and learning of language; and language teaching benefits "from the resources, methods, and insights provided by CL [corpus linguistics]" (Roemer, n.d., p.112). On the other hand, along with technology advancement, using new tools for language learning is inevitable. Among these technologies and tools are computers and concordancers respectively. On a computer, a concordancing program is used to investigate different kinds of corpora (i.e. large body of texts). Computer tools can assist the applying of a language learning methodology which is oriented toward authenticity in contexts and contents (Rüschoff, n.d.).

The pedagogical approach that studies corpora by software programs named concordancer, usually on computers, in order to identify regular patterns, is called DDL. Johns (1991) by arguing that the innovative aspect in DDL is that "'research [to the large quantities of text] is too serious to be left to the researchers": that the language-learner is also, essentially, a research worker whose learning needs to be driven by access to linguistic data" (p.2), introduced, first, DDL to describe his approach.

Lee (2011) believes that, in the DDL approach, students can work with a concordancer either individually or in groups, and they are not viewed as passive learners. By using a concordancer, students can find how some linguistic features are emphasized. concordancing "flavours learning by discovery" (p.401), and through it, students are able to "develop appropriate learning strategies" (p.401). It makes learning process become more exploratory, motivating, and experiential. Since students are confronted with lots of examples of specific forms, they, themselves, through inductive learning, generalize rules and finally test them. Therefore, they develop their knowledge of English. He also states that "DDL is helpful for students both in preparing for their exams and also for their general English acquisition because they can learn English in context and are interested in doing so" ( p.406).

In the DDL approach, language learners do not need to rely on the researcher as providers of corpus-based materials, but they, themselves, get the ability to work with corpora and concordancers and find patterns and behavior of words and phrases in such a way that can gain autonomy. DDL activities also bring about awareness-raising in language learners (Roemer, n.d.).

Jafarpour and Koosha (2006) claim that "the main advantage of the DDL is that learners of a language can get access to authentic text from a corpus and interact with a corpus database that provides comprehensive input to the second or foreign language learner" (p.22) [italics added]. It also provides a lot of contexts, and therefore provides opportunity for students to learn through "discovery learning and problem solving" mode (p.23). Regarding concordancing, they suggest that it is possible to use concordancers with any text. As a result, the concordancer "opens language classes to the use and integration of up-to-date and often authentic language even at lower levels" (p.23).

Collecting more than 90 studies of DDL (Boulton, 2010b), Boulton (2011) classified them into four groups by their objectives (most studies had more than one focus):

a. 54 studies of learners' attitudes: learners are receptive to DDL

b. 44 studies of learners' behavior: learners work successfully with corpora

c. 32 studies of learning outcomes: DDL is more effective than learning through other approaches

d. 24 studies of using corpora as a reference resource: referring to corpora helps learners in their writing, errorcorrection, translation for specific purposes

Regarding DDL, we have come to the conclusion that "DDL researchers certainly make no claim it is a panacea ... or that it should be used to the exclusion of other techniques ... but [teachers/researchers] ultimately have but one option: to try it out. (Boulton, 2011, p.6)

\section{Method}

\subsection{Participants}

Forty one learners participated in this study. All participants were studying English at Farhang English language Institution in Talesh, Iran, and were native speakers of Persian. In fact, two intact (one twenty-student and another twenty-one-student) classes were selected. One of these two classes was randomly selected as a control group and another as a treatment group.

Participants' ages were 16 to 18 , and they were all male, high school students. Gender was not considered as a moderator variable in this study. English was the medium of instruction in these classes. They had already studied English for 5 to 7 years; with a mean of 6 years. They had studied both let's go series and Interchange series for three years and had just entered the Passage series, which is a higher level than Interchange series and the learners were to know at least 3000 English words. The main reason for choosing these subjects was that they attended English classes 
six terms per year, six weeks per term, and three sessions per week. In other words, they took about 150 hours of English classes for one year. Thus, they had a greater chance to improve their lexical appropriateness. The coursebook that they were studying was Passages 1 (Richards, 2008). The classes were held for 34 sessions and each session was 90 minutes. In each session about 30 minutes were devoted to the SP instruction. It is worth noting that students were taught American English. British English was paid attention to, though. Both groups were taught by the same teacher.

\subsection{Materials}

For training, verbs were chosen from Passages 1 (Richards, 2008) - the book that they were taught as their coursebook. Words whose SPs were investigated were chosen based on the following conditions:

Words presented in context: Words which were presented in the book (Passages 1, Richards, 2008)

Semantic sets/clusters: Synonyms of selected words, from Oxford Learner's Thesaurus Dictionary

As a case in point, when the word USE was taken from the book for identifying its prosodic behavior, its synonyms (i.e. EMPLOY, DRAW ON/UPON, EXERT, MAKE USE OF, UTILIZE, and RESORT TO) were also under investigation so that the students were to investigate SP of the whole synonym set.

There were also some words in the test which were not available in the coursebook. The reason for this was to encourage students to pay attention to SP of words in every English text that they came across.

A pilot study for 6 weeks (one institute semester) was carried out. The pilot participants, 12 male EFL learners, were very similar to the main study participants. Vocabulary Choice Appropriateness Test (appendix A) was piloted in the pilot study. The quality of tests was proved as a result of the piloting- some items were deleted and some other items were changed. To calculate the reliability, Kuder-Richardson formula (KR-21) was run. The reliability estimate for vocabulary choice appropriateness test was 0.86 , which meant the test was reliable.

The test included 30 multiple choice items with three choices as it was supposed that the prosodic behavior of a word could be one of three behaviors: positive, neutral, negative. There was no penalty for guessing. The actual examples in the test came mainly from corpora which were used in the study. An example of vocabulary choice appropriateness test is presented here:

Sentence: The constantly threatening nuclear war will ---------.

Original word: break out

Near-synonym set: \{start, develop, break out

It is the advantage of this kind of tests that the teachers, as Odlin (1994) states, do not need to use the statement such as in this context this answer "'is likely to be used"', instead the teacher has a previously-used (original) answer to the test item "which can lead to a genuine examination of the reasons ... underlying the choice" (p.294) [Italics added]. A choice which entailed decisions of appropriateness rather than correctness.

Each test item was then applied to predict an answer (the most appropriate near-synonym) that could fill the gap. The possible candidates were three near-synonyms (including the original word) in the given set. In this study, the original word was considered as the correct answer. The proposed answers could then be evaluated by examining whether they could restore the original word by filling the gap with the most appropriate near-synonym.

Ideally, the correct answers should be provided by human experts. To check the validity of test, it was sent to some native speakers of English for human judges, to select the missing words. The results ( 5 native speakers answered the test and sent it back) showed that the agreement between the five judges was high (about $85 \%$ ), but not perfect. The agreement between each native speaker's judgment and the original word was also high (about $85 \%$ ). The human judges were allowed to choose more than one correct answer when they were convinced that more than one near-synonym fitted well in the context. They used this option sparingly, only in 2 items (about $6 \%$ ) of the 30 sentences.

In the treatment group, to find semantic behavior of lexical items, the Brown corpus and BNC (100 million words) were chosen. They were chosen because they were easily available, they had been used in previous studies; they were also manageable and easy enough to use. BNC is a part-of-speech tagged corpus which is helpful for extracting collocations relevant for a synonym set. It was used as a supplementary corpus in this study.

It is worth noting that semantic prosodies of lexical items were supposed to be examined in general English environment. Using the general corpus helps to control genre.

In order to control the register differences among near synonyms, it had been tried to select those near-synonyms (from each set) which were in the same register. Also, in order to control the effect of grammatical form on prosodic behavior of verbs, only the main form of the verbs had been investigated in corpora. However, in some rare situations, when past or past participle form of verbs had been used, it had been made sure that different grammatical forms did not have any effect on SP of the verbs.

\subsection{Treatment}

The positive, neutral, and negative prosodies were taken like Xiao and Mcenery (2006), corresponding to Partington's (2004) favorable, neutral, and unfavorable prosodies.

Students, in the treatment group, were provided regular teaching of SP of verbs which they came across during their lessons. In fact, verbs were chosen by the teacher. The learners were also provided training in using corpora and concordancer mainly at the beginning of the study and also during the study in order to find SP of items by themselves. The teacher advised them, helped them, and gave them useful feedback. 
To create a DDL-friendly environment, the institution was equipped with an online wireless internet connection so that students had access to online corpora and their concordances; nearly all students had access to online internet at their homes, too. During the class sessions, some laptop computers were provided by the students and the teacher to work with corpora through concordancing software.

To make DDL coherent, a set of concordance lines were displayed for presenting idea, followed by complete sentence examples for comprehension. Also, in order to motivate students and to prevent them from over loading, fewer examples were presented at the beginning.

For each verb, in the treatment group, students were given, at first, the near synonyms of the selected verb in a dictionary of synonyms (Oxford Learner's Thesaurus); then were required to find SP of the verb and its near synonyms through the DDL approach for comparative purposes, so that they would know that, in a synonym set, which word had a positive, which word had a neutral and which word had a negative SP. For example working on the word USE (mentioned above), extracted from the coursebook, along with its synonyms, students reported that EMPLOY had a positive, RESORT TO a negative, and others had a neutral SP. In vocabulary choice appropriateness tests, students were required to choose a verb with its appropriate prosodic condition.

Students were asked first to examine the concordance lines with keyword-in-context where the keywords were arranged below each other on the center of the page, with a fixed number of words which provided context to the both left and right side of the keyword. The learners were allowed to use dictionaries to get the meaning of new vocabulary. However, they were encouraged to focus on the words in the middle of the page so that they did not have to translate every words that did not understand. After checking the students' analysis, if needed, the teacher presented another analysis. At this stage, students compared answers and gained knowledge of how to recognize the prosodic behavior of the verb. Having done the exercise, students were able to find out the SP which applied to the lexical items. The teacher easily gave feedback by presenting commentaries in the class. The quick way of commenting helped the teacher to monitor the learning process of the student without spending hours on correcting assignments. Consequently, through practical exploring of corpora and concordances over time, the students got autonomous.

A note of caution should be stated here that sometimes a word has a positive SP, but it collocates with negative words (semantic preference); that is to say, SP is not the characteristic of the collocated word, but the characteristic of the whole unit. However, in this study, to discover SP of a specific word, the learners had to figure it out from its collocations. For example, the word GIVE UP would a have positive SP if it almost always collocated with negative words and a negative SP if it collocated with positive words. On the contrary, the word INSIST ON would have negative SP if it collocated with negative words and positive SP if it collocated with positive words.

In the control group, students were given the same lexical items and their synonyms from the same dictionary. The concept of SP was explained to them. However, they learned SP of vocabulary traditionally, and without using a DDL approach. That is, to find the prosodic difference between near-synonyms, they were expected to check the difference through dictionaries and the definitions that dictionaries presented or through Persian equivalents of near-synonyms, or through their intuitions. In the control group, too, the (same) teacher advised learners, helped them, and gave them useful feedback.

In both groups, the same number of synonym-sets (about 5) were presented during each session; the overall number was about 150, and about 20 sets of them were tested in the posttest. However, sometimes, the students were to complete their class activities as homework. In both groups, verb synonym-sets and the difference among them were taught for the receptive mode. The time on task for the groups of study was controlled as both groups had taken equal time to do the related activities. It should be mentioned that both groups had not been exposed to SP until the beginning of the study. They even did not know what the semantic prosody was.

Although the nature of the present study was not qualitative, it was found useful as a complement to the quantitative tests, to speak shortly with participants in order to gain understandings into any unexpected findings about the participants' experiences. Therefore, in the second part of the study, qualitative stage, all participants were interviewed briefly and individually. In brief, semi-structured interviews, specific questions and their sequence were determined in advance. Subjects were allowed to speak in either English or Persian, whichever allowed them to express their ideas more clearly.

\subsection{Procedure}

Before administering the pretests, students in both groups read a consent form that explained the purpose of the study and they agreed to participate. To the both classes, the pretests were given which consisted of 30 multiple-choice items. At the end of the study, the posttest (the same test) was given to the students. Subjects were required to answer to the tests in 20 minutes.

At the end of the study, both groups were interviewed informally. Interviewing was used to elicit the participants' attitude, opinions, and evaluations of the method being used. Both groups were questioned about their feelings and insights about the method that they used to find the SP of words, the control group was also questioned about the ways they used to do so.

\subsection{Data Analyses}

In this study, there were one dependent variable (EFL learners' vocabulary choice appropriateness) and two independent variables (teaching SP of English verbs through data-driven learning, and teaching SP of English verbs traditionally). To compare means of each test within and between subjects, a repeated-measures ANOVA was used to analyze the data. All of these assumptions such as skewedness for this statistic were met. In this calculation, the alpha level was set to .05 . 


\section{Result}

Statistics for vocabulary choice appropriateness test score, for both groups, are presented in Table 2. In the control group, the means improved slightly from 7.85 to 8.65 . The standard deviation (SD) remained almost stable (1.424 and 1.755). In the treatment group, the means, from the pretest to the posttest, improved from 8.14 to 13.43 . Here, too, the standard deviation (SD) remained almost stable (1.824 and 2.181).

Table 2. Descriptive Statistics of Vocabulary Choice Appropriateness Test

\begin{tabular}{ccccc}
\hline & GROUP & Mean & Std. Deviation & N \\
\hline Pretest & control & 7.85 & 1.424 & 20 \\
& treatment & 8.14 & 1.824 & 21 \\
& total/average & 8.00 & 1.628 & 41 \\
Posttest & control & 8.65 & 1.755 & 20 \\
& treatment & 13.43 & 2.181 & 21 \\
& total/average & 11.10 & 3.113 & 41
\end{tabular}

Table 2 shows that, in the control group, there was no significant improvement $(M=8.65-7.85=-0.800)$ from pre-test to post-test, but in the treatment group there was $(\mathrm{M}=13.43-8.14=-5.29)(55$ percent $)$.

Table 3. Repeated-measures ANOVA (Tests of Within-Subjects Contrasts)

\begin{tabular}{ccccccc}
\hline Source & TES & $\begin{array}{c}\text { Type III } \\
\text { Sum of } \\
\text { Squares }\end{array}$ & df & $\begin{array}{c}\text { Mean } \\
\text { Square }\end{array}$ & F & Sig. \\
\hline TEST & $\begin{array}{c}\text { Linea } \\
\mathrm{r}\end{array}$ & 189.696 & 1 & 189.696 & 109.209 & .000 \\
TEST * & Linea & 103.062 & 1 & 103.062 & 59.333 & .000 \\
GROUP & $\mathrm{r}$ & & & & & \\
Error(TEST) & Linea & 67.743 & 39 & 1.737 & & \\
& $\mathrm{r}$ & & & & & \\
\hline
\end{tabular}

Table 4. Repeated-measures ANOVA (Tests of Between-Subjects Effects)

\begin{tabular}{llllll}
\hline Source & $\begin{array}{l}\text { Type III } \\
\text { Sum of } \\
\text { Squares }\end{array}$ & df & $\begin{array}{l}\text { Mean } \\
\text { Square }\end{array}$ & F & Sig. \\
\hline Intercep & 7423.929 & 1 & 7423.929 & 1515.314 & .000 \\
$\mathbf{t}$ & & 1 & 131.733 & 26.888 & .000 \\
GROUP & 131.733 & 49 & 4.899 & & \\
Error & 191.071 & 39 & & & \\
\hline
\end{tabular}

The result also showed that the interaction was highly significant: $F=59.33, d f=1,39, p<0.05$ (in the repeated-measures ANOVA) (tables 3 and 4), and the differences were larger than what was expected. 


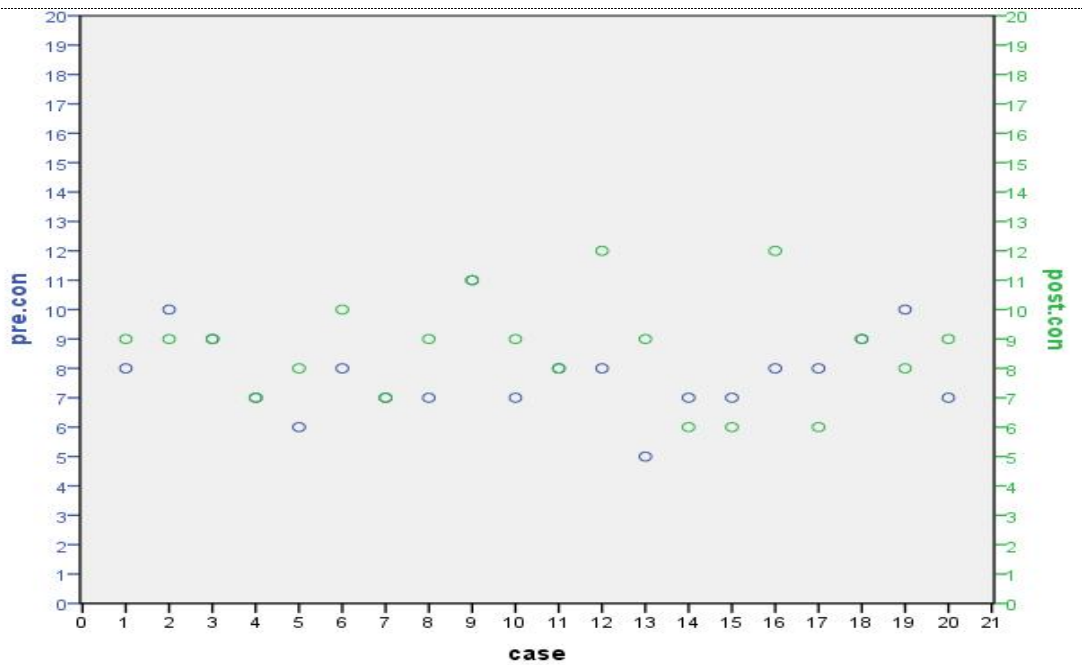

Figure 1. The comparison of each student's scores in the pretest and posttest (control group)

Figure 1 shows that, in the control group, the scores in the posttest exhibit the same histogram as those of the pretest, on vocabulary choice appropriateness; and those of the posttest are slightly better than the pretest. Students (3), (4), (7), (9), (11), and (18) had the same score on both tests, though.

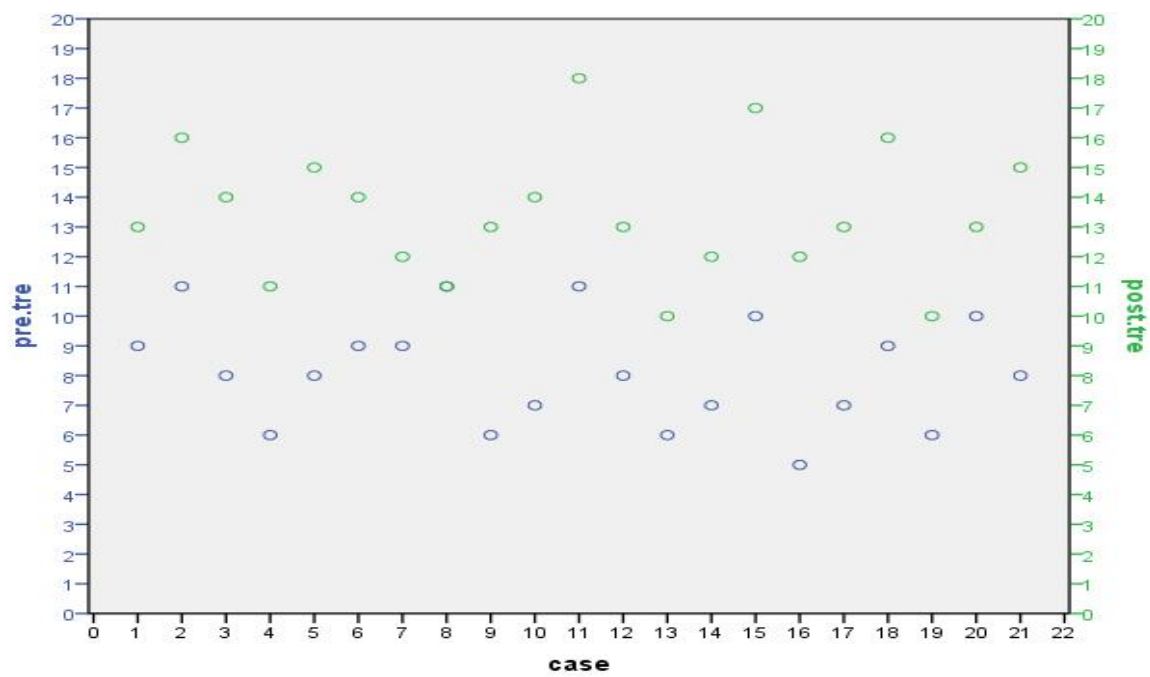

Figure 2. The comparison of each student's scores in the pretest and posttest (treatment group)

Figure 2 indicates that most of the learners' vocabulary choice appropriateness test score in the posttest increased. Except one student (8), all students were able to boost their scores 3 to 7 numbers.

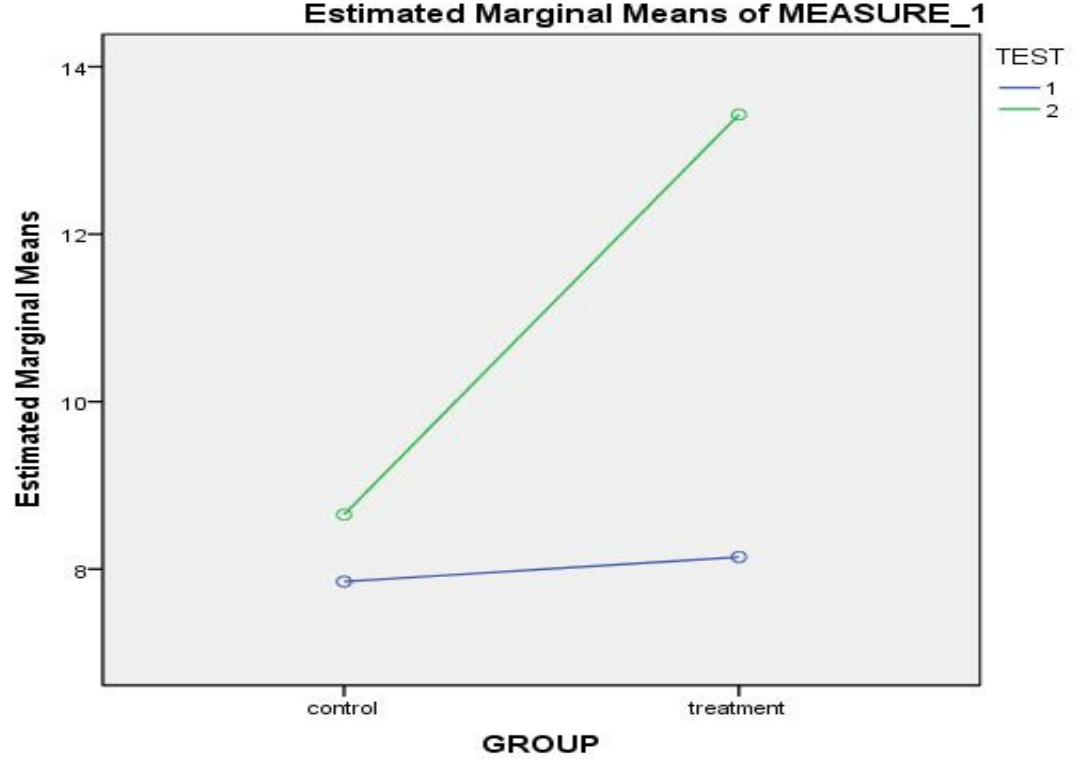

Figure 3. The comparison of improvement in the pretest (test 1) and posttest (test 2) 


\section{Discussion}

The results of the present study showed that, in both groups, before the study, the participants' overall performance on vocabulary choice appropriateness (based on SP) was poor; the mean score was 7.85 and 8.14 out of 20 respectively for the control and treatment groups. However, the EFL learners' vocabulary choice appropriateness ability improved significantly, in the treatment group, after a 34-session teaching SP (as a discriminative training for near-synonym substitution) through the DDL approach.

In the treatment group, the participants' vocabulary choice appropriateness ability improved significantly by learning prosodic behavior of verbs through the DDL approach: they increased their mean (5.29 scores). Consequently, it was proved that the DDL approach is an effective way for teaching SP of verbs. Also, DDL gave EFL learners the opportunity to surpass native English speakers in recognizing prosodic behavior of English verbs as some learners in the treatment group, in the posttest, performed better than native English speakers in vocabulary choice appropriateness test.

In the control group, the participants slightly improved their mean scores $(0.800)$ on vocabulary choice appropriateness through traditional instruction of SP, but the improvement was not significant. It means that traditional teaching of SP is not helpful for students to find out prosodic behavior of English vocabulary. That is, dictionaries, whether EnglishEnglish or English-Persian ones, are not helpful for learning prosodic behavior of English verbs. They have not introduced the prosodic behavior of verbs. Plus, Persian EFL learners are not successful in identifying prosodic behavior of English vocabulary through their intuitions.

The results of the control group supported the research hypothesis that EFL learners' vocabulary choice appropriateness was improved by SP learning through the DDL approach: in the control group, students did not use the DDL approach to learn SP. As a result, their posttest score did not change significantly. This indicates that the EFL learners' improvement on vocabulary choice appropriateness test, in the treatment group, was not the effect of teaching SP alone, but teaching SP through the DDL approach. It also indicates that the EFL learners' improvement, in the treatment group, was not the effect of normal classroom teaching, or of taking the test twice since if this was the case, the control group should have had the same improvement.

\subsection{Findings from the interviews}

Almost all participants in the treatment group felt that DDL could help in improving their English ability. Generally, the participants found it more interesting, but a few number of students found it confusing and difficult. The attitudes toward DDL were more positive than negative. All the students, even those who, at first, seemed least motivated, were working eagerly on the activities. It was discovered that participants tended to work in pairs or groups. However, Participants did feel that the DDL approach would make them more autonomous and active.

Nearly all participants in the control group claimed that they used dictionaries as their tools for learning the prosodic behavior of vocabulary; and those who had better function in the posttest claimed using English-English dictionary definitions. Generally, they found it frustrating and a hard task. Additionally, participants with lower test score claimed using English-Persian dictionaries or their intuitions (in order to find SP through Persian equivalents).

In order to appropriately address the results of vocabulary choice appropriateness, they should be interpreted with caution, though.

\subsection{Differences in vocabulary choice appropriateness test scores}

Possible explanations for the noticeable differences within treatment group may be found by considering the following three factors:

1- Participants' expectations

2- Measurement

3- Number of the verbs under investigation

First, students may have expected some improvement in their vocabulary choice ability after the treatment. This is because the purposes of the study and of the instruction were explained to them before the treatment. In addition, the consent form they read revealed the purpose of the study.

Second, the vocabulary choice appropriateness results could be different depending on the way they were measured. In this study, a 30-item test in semantic prosody was constructed and the scores of students in answering questions were considered as a method for measuring vocabulary choice appropriateness. In addition, instead of four-choice items, three-choice items were provided that have made the test quite easier.

Third, since the verbs under investigation were limited to the verbs in the book (Passages 1) in order to find their prosodic behavior, the number of semantic sets which were under investigation was also considerably small.

As it was already mentioned, there was a slight improvement in control group, though. There are 3 reasons for this:

1- The improvement was because of taking the test twice which seems highly improbable because there was a 3month gap between pre-test and post test.

2- The improvement was as a result of the method (fining out the difference among near-synonyms mostly through dictionaries) in control group; this seems reasonable because some English-English dictionaries imply the negative or positive prosodic behavior of their items. This is true since when interviewing students, those who had slight improvement in posttest stated that they had used English-English dictionary definitions, on the contrary to those who had used English-Persian dictionaries, that is, had used translation for investigating the difference among near-synonyms, had no improvement. 
3- Participants' vocabulary choice appropriateness test score improved because of the effect of normal classroom teaching.

\subsection{Results Compared with the Research Hypothesis}

The hypothesis, that teaching SP of English verbs through the DDL approach has a significant effect on the improvement of EFL learners' vocabulary choice appropriateness, is confirmed and accepted. The differences, in the treatment group, were significant in the repeated-measures ANOVA. Test results showed that participants, in the treatment group, improved their scores in the posttest by learning SP of English verbs through the DDL approach. This improvement was supported by control group's low score in the posttest.

\section{Conclusion}

\subsection{Implications and Recommendations for Teaching}

The first outcome of the present study is that it is possible to teach SP of vocabulary and consequently it is possible to learn prosodic behavior of vocabulary consciously.

As it was shown that near-synonyms have different prosodic behavior, teachers should be cautious in introducing new English vocabulary by giving synonyms of it.

While learning vocabulary, EFL learners have to take into account SP of verbs especially in synonym-sets. The study also suggests that the DDL approach is a better way for finding out the prosodic behavior of English words.

In classes with the same background language, teachers should be cautious about using the EFL learners' background language in order to introduce prosodic behavior of vocabulary.

Textbook writers should pay enough attention to the prosodic behavior of vocabulary in that they should make use of authentic materials in their textbooks so that words are used in their appropriate prosodic behavior.

As nowadays it is common to evaluate vocabulary knowledge of EFL learners by asking for its synonyms, test designers are suggested to use words with the same SP to avoid negative backwash effect of the test.

English-Persian dictionaries have not paid serious attention to prosodic feature of vocabulary at least verbs in choosing Persian equivalents. Therefore, to lexicographers, this study suggests considering prosodic behavior of vocabulary in selecting equivalents from different languages.

\subsection{Limitations}

Participants were male learners. No female learners were able to participate in this study for institutions in Iran are not allowed to hold mixed classes. Only students of English Language institution of Farhang participated in the study.

Since the formation of new classes, because of its expenditure and institutional issues, was not possible and because using natural classes is becoming prominent nowadays, two intact (a twenty-one-student and another twenty-student) classes were selected.

\subsection{Suggestions for Future Study}

This study used verb near-synonyms. Future researchers may work on other parts of speech such as nouns and adjectives. The test conducted and the study itself were in receptive mode, further research can investigate SP in productive mode.

Further research might be conducted on female learners, and/or using extensive interviews or case studies as a technique for data collection, and/or using different (numbers of) corpora.

\section{References}

Ahmadian, M., Yazdani, H. \& Darabi, A. (2011). Assessing English learners' knowledge of semantic prosody through a corpus-driven design of semantic prosody test. English Language Teaching, 4(4), 288-298.

Bednarek, M. (2008). Semantic preference and semantic prosody re-examined. Corpus Linguistics and Linguistic Theory, 4(2), 113-139.

Boulton, A. (2011). Blending research methods: Qualitative and quantitative approaches to researching computer corpora for language learning. Proceedings of KAMALL 2011: New Directions for Blended Learning in EFL. Daejeon: KAMALL, 1-9.

Boulton, A. (2010b). Learning outcomes from corpus consultation. In M. Moreno Jaén, F. Serrano Valverde \& M. Calzada Pérez (Eds.), Exploring new paths in language pedagogy: Lexis and corpus-based language teaching (pp.129144). London: Equinox.

Fan, P. (2010). Lexical acquisition viewed from a contrastive analysis of collocational behavior of near synonyms. Chinese Journal of Applied Linguistics, 33(5), 52-64.

Flowerdew, L. (2009). Applying corpus linguistics to pedagogy: A critical evaluation. International Journal of Corpus Linguistics, 14(3), 393-417.

Guo, X., Zheng, L., Zhu, L., Yang, Zh., Chen, Ch., Zhang, L., Ma, W. \& Dienes, Z. (2011). Acquisition of conscious and unconscious knowledge of semantic prosody. Consciousness and Cognition, 20(2), 417-425.

Inkpen, D. (2007). A statistical model for near-synonym choice. ACM Transactions on Speech and Language Processing, 4 (1), 1-17. 
Inkpen, D. Z. \& Hirst, G. (2002). Acquiring collocations for lexical choice between near-synonyms. Proceedings of the Workshop on Unsupervised Lexical Acquisition, $40^{\text {th }}$ Annual Meeting of the Association for Computational Linguistics (ACL 2002), Philadelphia, 67-76.

Inkpen, D. \& Hirst, G. (2006). Building and using a lexical knowledge-base of near-synonym differences. Computational Linguistics, 32 (2).

Jafarpour, A. A. \& Koosha, M. (2006). Data-driven learning and teaching collocation of prepositions: The case of Iranian EFL students. Research on Foreign languages/Journal of Faculty of Letters and Humanities, 200, 1-30.

Johns, T. (1991). Should you be persuaded: Two samples of data-driven learning materials. In T. Johns \& P. King (Eds.), Classroom Concordancing. ELR Journal, 4, 1-16.

Lewandowska-Tomaszczyk, B. (1996). Cross-linguistic and language specific aspects of semantic prosody. Language Sciences, 18 (1-2), 153-178.

Lee, H-C. (2011). In defense of concordancing: An application of data-driven learning in Taiwan. Procedia Social and Behavioral Sciences, 12, 399-408.

Lee, H-C., \& Liu, J. (2009). Effects of collocation information on learning lexical semantics for near synonym distinction. Computational Linguistics and Chinese Language Processing, 14 (2), 205-220.

Louw, B. (2000). Contextual prosodic theory: Bringing semantic prosodies to life. In C. Heffer, H. Sauntson, (Eds.), Words in Context: A Tribute to John Sinclair on his Retirement. Birmingham: University of Birmingham.

Louw, B. \& Chateau, C. (2010). Semantic prosody for the $21^{\text {st }}$ century: Are prosodies smoothed in academic contexts? A contextual prosodic theoretical perspective. Proceedings of $10^{\text {th }}$ International Conference on Statistical Analysis of Corpus Study, 755-764.

Odlin, T. (1994). Perspectives on pedagogical grammar. In T. Johns (Eds.), From printout to handout: Grammar and vocabulary teaching in the context of data-driven learning (pp.293-318). Cambridge: Cambridge University Press.

Partington, A. (2004). "Utterly content in each other's company": Semantic prosody and semantic preference. International Journal of Corpus Linguistics, 9 (1), 131-56.

Philip, G. (2010). Why prosodies aren't always present: Insights into the idiom principle. [Online] Available: http://ucrel.lancs.ac.uk/publications/cl2009/317_FullPaper.rtf (August 15, 2012).

Reinhardt, J. (2010). The potential of corpus-informed L2 pedagogy. Studies in Hispanic and Lusophone Linguistics, 3 (1), 239- 251.

Richards, J. C. \& Sandy, C. (2008). Passages ( $2^{\text {nd }}$ ed.). Cambridge: Cambridge University Press.

Richards, J. C. \& Renandya, W. A. (2002). Methodology in language teaching. Cambridge: Cambridge University Press.

Roemer, U. (n.d.). Corpora and language teaching. [Online] Available: http://www.uteroemer.com/HSK_Roemer_ uncorrected_proofs.pdf (August 15, 2012).

Rüschoff, B. (n.d.). Data-driven learning (DDL). [Online] Available:

http://archive.ecml.at/projects/voll/rationale_and_help/booklets/resources/menu_booklet_ddl.htm (December 19, 2012)

Sinclair, J. (1991). Corpus, concordance, and collocation. Oxford: Oxford University Press.

Stewart, D. (2010). Semantic prosody: A critical evaluation. New York: Routledge.

Watter, E. (1992). Semantic set-defining: Benefits to the lexicographer and the user. [Online] Available: http://www.euralex.org/elx_proceedings/Euralex.pdf (September 22, 2012)

Xiao, Z., \& McEnery, A. (2006). Collocation, semantic prosody and near synonymy: A cross-linguistic perspective. Applied linguistics, 27 (1), 103-199.

Zethsen, K. K. (2006). Semantic prosody: Creating awareness about a versatile tool. Tidsskrift for Sprogforskning ,4 (12), 275-294.

Zhang, C. (2010). An overview of corpus-based studies of semantic prosody. Asian Social Science, 6 (6), 190196.

Zhang, W. (2009). Semantic prosody and ESL/EFL vocabulary pedagogy. TESL Canada Journal, 26 (2), 1-12.

http://corpus.byu.edu/bnc/

http://www.lextutor.ca/concordancers/concord_e.html 
Appendix A

The items selected for the test includes those cases of SP whose conditions (positive, negative or neutral) have already been determined by different researchers (the first 10 items) or have been determined by the teacher (items 11-30).

1. While being inexpensive and readily transportable, vacuum-formed plastic pools do have the disadvantage of flexibility which can---------- problems during installation.
a. cause
b. bring about
c. lead to

2. Despair seems to have -------- among the team.
a. taken place
b. set in
c. come about

3. The small shops must be retained for they -------- essential service to the community.
a. provide
b. supply
c. issue

4. He ------- to make/making life difficult for me.
a. is bent on
b. is determined
c. is resolved

5. Whoever is born of God does not -------- $\sin$.
a. practice
b. commit
c. perform

6. The organization has -------- the myth all over the word.
a. spread
b. communicated
c. peddled

7. I could just ---------- a reputation for myself and make some real money.
a. accumulate
b. pile up
c. build up

8. There were several fairly good minor portraits in the play, including Katherine Squire's vigorous characterization of a farm mother who --------- no hifalutin nonsense from her daughter, or anyone else.
a. allowed
b. brooked
c. accepted

9. The constantly threatening nuclear war will
a. start
b. develop
c. break out

10. "You see", she said, looking past him into the room, where the highlight glasses sparkled dully in the bright light, "you and I can't understand the many hardships they have to ---------.
a. undergo
b. experience
c. have

11. Strict local rules of pleading cannot be used to ---------- unnecessary burdens upon rights of recovery authorized by federal law.
a. apply
b. impose
c. enforce

12. We are evidently trying hard to think of new ways to ---------- the problem of fear these days.
a. handle
b. see to
c. deal with

13. Only under rare circumstances would a bride an orgasm during her first intercourse.
a. suffer
b. run into
c. experience

14. Changes in light and color will --------- a variety of visual designs.
a. trigger
b. set off
c. spark

15. Leadership is lacking in our society because it has no legitimate place to
a. break out
b. erupt
c. develop

16. The dispute has on for months.
a. dragged
b. kept
c. carried

17. The two cities have the examples of Little Rock and New Orleans to hold up as warnings against resorting to violence to try to --------- the processes of desegregation.
a. avert
b. avoid
c. stop

18. Availability of housing and social facilities with the creation of an attractive environment would attract industry and commerce, and hence --------- the creation of jobs.
a. result in
b. bring about
c. cause

19. The road's engineers ---------- further improvement when the turnpike is extended into Boston.
a. await
b. anticipate
c. look for

20. And some of the fragrant molecules are inhaled, thus stimulating smell receptors connected to the part of our brains which ---------- our emotions, well-being and many other bodily functions.
a. controls
b. curbs
c. contains

21. Fulham --------- one of her worst raids of the war.
a. got
b. received
c. reaped

22. In order to secure the payment of tribute, servicemen would often ---------- taking/to take hostages.
a. resort to
b. employ
c. use
What do you think he means by remembrance? He doesn't ---------- his friends.
a. forget
b. wipe
c. blot out

23.Eire is planning to use its forthcoming Presidency of the European Commission to press Britain to major upgrading of road and rail links between North Wales.
a. embark on
b. start
c. commence

24. The students who are most willing to --------- the suppression of civil liberties are also those who are most likely to be prejudiced against minority groups.
a. agree with
b. go along with
c. acquiesce in 
25. The primordial deity, Nun, advised Re to use this powerful Eye, the sun itself and possessor of its own complex mythology, to --------- vengeance on the evildoers, and furthermore to send the Eye in the person of Hathor.
a. hold out for
b. exact
c. press for

26. If the washing machine wrong, it will diagnose the problem itself.

a. becomes

b. goes

c. gets

27. The speed of change was such that it had become difficult to not yet seen the end.

a. keep up with

b. proceed

c. go on with

28. We'd very much like to hear from others who have ---------- profitable solutions to this seasonal problem.
a. dreamt up
b. conceived
c. come up with

29. Not only was Haumd's intonation and phrasing without flaw, but [also] he seemed to

every tonal eccentricity.
a. look after
b. take ... in stride
c. take care of 